Provided for non-commercial research and education use. Not for reproduction, distribution or commercial use.

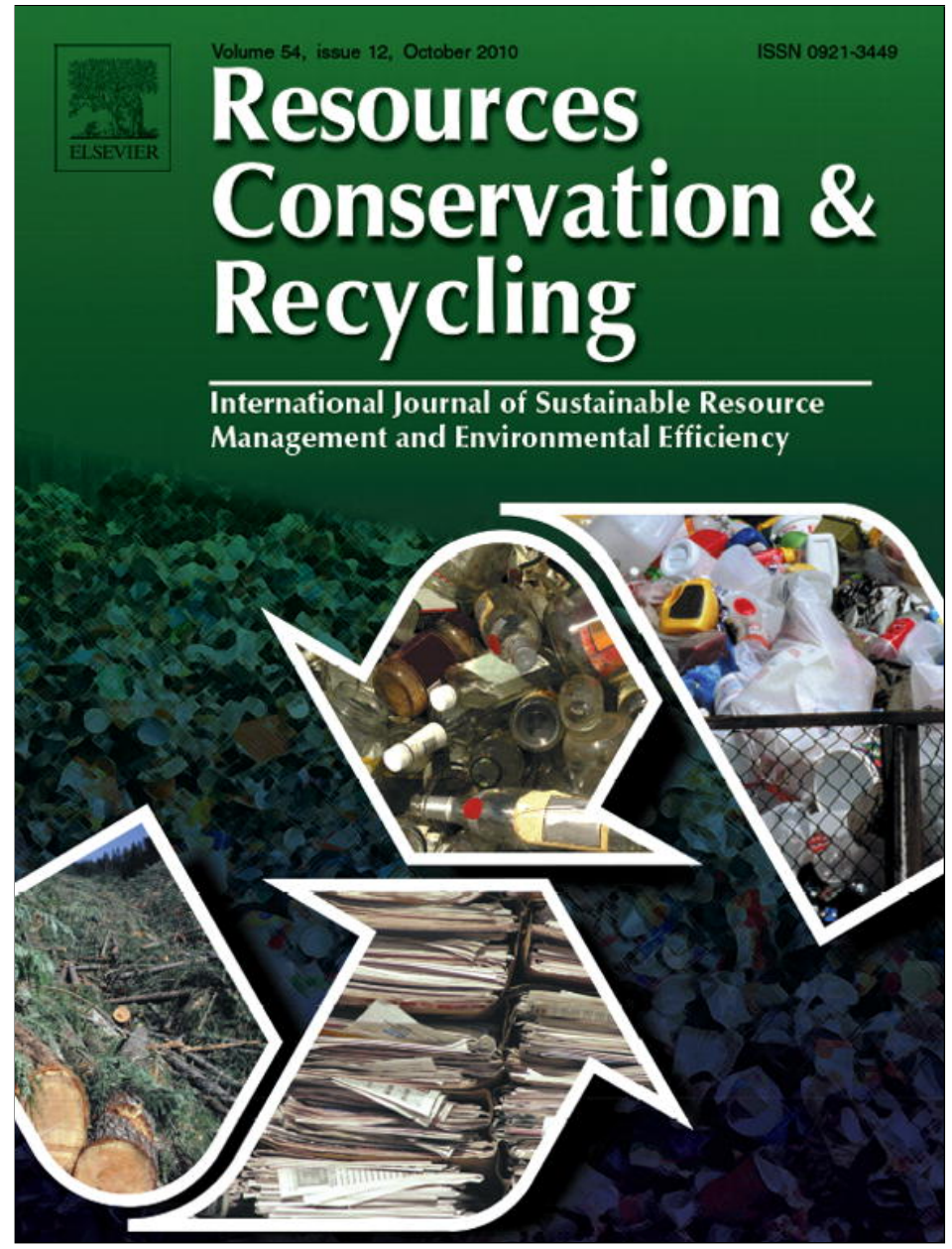

This article appeared in a journal published by Elsevier. The attached copy is furnished to the author for internal non-commercial research and education use, including for instruction at the authors institution and sharing with colleagues.

Other uses, including reproduction and distribution, or selling or licensing copies, or posting to personal, institutional or third party websites are prohibited.

In most cases authors are permitted to post their version of the article (e.g. in Word or Tex form) to their personal website or institutional repository. Authors requiring further information regarding Elsevier's archiving and manuscript policies are encouraged to visit:

http://www.elsevier.com/copyright 


\title{
LCA allocation procedure used as an incitative method for waste recycling: An application to mineral additions in concrete
}

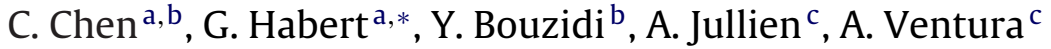 \\ a Université Paris-Est, LCPC, 58 Bd Lefebvre, 75732 Paris, France \\ ${ }^{\mathrm{b}}$ UTT, Institut Charles Delaunay, FRE CNRS 2848, CREIDD, 12, Rue Marie Curie - BP 2060, 10010 Troyes, France \\ ${ }^{\mathrm{c}}$ LCPC/DDGC, Route de Bouaye, BP 412944341 Bouguenais, France
}

\section{A R T I C L E I N F O}

\section{Article history:}

Received 14 September 2009

Received in revised form 7 April 2010

Accepted 10 April 2010

\section{Keywords:}

LCA

Allocation

Cement

Fly ash

Blast furnace slag

\begin{abstract}
A B S T R A C T
Waste recycling avoids waste landfilling and all associated releases. It also allows for saving nonrenewable resources. However, the new commercial interest for waste can be seen as a shift in their status from waste to co-product. This has important consequences for environmental load allocation between the different industrial products (and co-products) in industrial plants. In this paper, the specific case of cement has been studied. Actually, to reduce the environmental impact of cement and concrete, industries have been engaged over the last 10 years to increase the replacement of Portland cement by alternative cementitious materials that are principally industrial waste or by-products. In this study, the environmental impacts of two different Supplementary Cementitious Materials (SCM), blast furnace slag and fly ash, are considered using Life Cycle Assessment methodology through a study of the influence of different allocation procedures on environmental impacts of SCM in concrete. Three allocation procedures are tested. In the first one, which is the current practice, no allocations are done. As for the two others, the environmental burdens of the system are respectively associated with the relative mass and some current economic values of the co-products and products. The results are discussed according to the specificity of the cement substitution products (SCM) and the driving forces that are identified for the use of these co-products. Then, a description investigation of another allocation procedure is proposed based on the fact that it is not the relative economic value that permits to evaluate the environmental burdens but the contrary. This last allocation procedure could be generalised for other waste recycling and be used as a regulation tool between the different industrial branches.
\end{abstract}

(c) 2010 Elsevier B.V. All rights reserved.

\section{Introduction}

\subsection{General background}

Resources preservation is incontestably one of the big challenges that humanity has to face in order to ensure sufficient standard of living for present and future generations without using up resources provided by natural environment. In this context, waste recycling has been considered as one topic to investigate because it avoids their disposal and the associated impacts and replaces non-renewable resources. This type of industrial activity has been extensively developed within the past 20 years. As a consequence, a recent European Union directive (EU, 2008) notes that: a waste may be regarded as by-product if the following conditions are met:

\footnotetext{
* Corresponding author.

E-mail address: guillaume.habert@lcpc.fr (G. Habert).
}

Condition (a) further use of the substance or object is certain; Condition $(b)$ the substance or object is produced as an integral part of a production process;

Condition (c) the substance or object can be used directly without any further processing other than normal industrial practice;

Condition (d) further use is lawful, i.e. the substance or object fulfils all relevant product, environmental and health protection requirements for the specific use and will not lead to overall adverse environmental or human health impacts.

This regulation thus will revise the status of waste as soon as it will be translated in national law, accounting that they can be economically profitable, and that they can generate pollution themselves. In order to find accordance between possible technical solutions for waste, and associated economical and environmental benefits, new assessment methods have to be developed.

Life Cycle Assessment (LCA) is a methodology for evaluating the environmental loads of processes and products during their life cycle, from cradle-to-grave. This methodology is based on international standards of series ISO 14040 (ISO, 2006). The purpose of our 
study is to investigate how LCA methodology can serve as a basis for decision helping taking into account economical and environmental interests. In LCA methodology, the key issue of waste recycling is the allocation procedure. In current LCA studies no environmental burdens are usually affected to waste production (except for their disposal), as they are unintentionally produced. However, according to the new above mentioned EU directive (EU, 2008), some waste should be now considered as by-products and thus be affected by an allocation coefficient. Indeed, in LCA when a production system produces several products, material and energy flows and the associated environmental burdens must be partitioned between them in order to accurately reflect their individual contribution to the environmental impacts. In the numerous studies that have developed allocation procedures, there does not seem to be any procedure that proves that any specific method is the 'correct' one (Finnveden, 1999). Although SETAC strongly recommends to rely the allocation procedure primarily upon physicochemical considerations (Lundie et al., 2007), this method is not always usable. Instead, arguments are usually based on what intuitively seems reasonable or fair. Thus, the choice of an allocation procedure has proven to be one of the most controversial methodological issues in LCA, largely because it can significantly influence the results of a study (e.g. Sayagh et al., 2010; Reap et al., 2008a; Weidema, 2001; Ekvall and Finnveden, 2001; Frichknecht, 2000). The ISO standard for LCA (ISO, 2006) states that when several alternative allocation procedures seem applicable, a sensitivity analysis should be conducted to illustrate the influence of the procedure on the results.

\subsection{Study objectives}

In that context, this paper first aims at comparing the effect of considering the new EU directive (EU, 2008) when calculating the environmental impacts associated to materials previously considered as waste after their status have been revised. This is done using both the no allocation procedure (waste status), as well as two other procedures: the mass ratio allocation between products and by-products and the economic ratio allocation.

A process based methodology is first defined to finely determine the allocation procedure principles using the concepts of primary and secondary processes. Then it calculates the corresponding environmental results for Supplementary Cementitious Materials (SCM) used in cement concrete with the different allocation methods. The discussion then focuses on the tested allocation procedures compared to another widely used method, the system expansion method. Finally, the possible use of the economic allocation procedure as a tool suitable for regulating the waste/byproducts recycling economy is analysed.

\section{Materials and methods: Life Cycle Assessment of mineral additions}

\subsection{Supplementary Cementitious Materials (SCM) used in cement concrete}

Concrete is the most widely used construction material on Earth. Human beings do not consume any other material in such tremendous quantities except for water. Current estimates of world production of cement are of the order of $2.5 \times 10^{9} \mathrm{t}$ per year (Kelly and Van Oss, 2008), which is enough to produce over one concrete cubic meter per person and per year (Gartner, 2004). This induces large environmental impacts, especially due to the use of Portland cement as the aggregate binder in the concrete. Actually, recent studies have confirmed that Portland cement was the primary source of $\mathrm{CO}_{2}$ generated by typical commercially produced concrete mixes, being responsible for $74-81 \%$ of concrete $\mathrm{CO}_{2}$ emis- sions (Flower and Sanjayan, 2007) and $\mathrm{CO}_{2}$ emissions from cement industry are considered to represent $5 \%$ of the total anthropogenic $\mathrm{CO}_{2}$ emissions (Hendricks et al., 1998). To reduce this environmental impact, cement and concrete industries have been engaged over the last 10 years to increase the replacement of Portland cement with Supplementary Cementitious Materials (SCM), which are principally industrial waste such as granulated blast furnace slag (GBFS) and coal combustion fly ashes (FA). If environmental impacts of cement have recently been investigated thoroughly (Gartner, 2004; Xing et al., 2008), those from SCM have been scarce (Kawai et al., 2005; Flower and Sanjayan, 2007) and reduced to the energy and consumption required for their processing because they are considered as waste. According to the European Union directive (EU, 2008) GBFS and FA have now to be regarded as by-product because they fulfil the above mentioned conditions.

Actually, their further use is certain which fulfils condition (a) of European directive (EU, 2008) as in some part of Europe such as France, the production GBFS is completely used in cement industry and the use of FA in cement industry is equal to $130 \%$ of its yearly production.

GBFS are made from the extraction of iron from iron ore in blast furnace, whereas it is not possible to produce iron without producing GBFS. As for FA, which are the unburnt particulates (mainly siliceous components) that are released in exhaust gas when coal is burnt in coal power plants. For sanitary reasons, these gases have to be cleaned from ashes which are removed and concentrates to form FA. Thus both materials are produced as an integral part of a production process and then fulfil the condition (b).

GBFS are vitrified with water and grinded. Fly ashes are only dried. Thus, they can be used directly without any further processing other than normal industrial practice which fulfils condition (c).

Finally, only GBFS and FA that are used in cement industry are those which fulfil existing standards that consider their suitability in terms of mechanical performance, risk for concrete durability and risk for the environment such as NF EN 450-1 standard for FA (CEN, 2007) and EN 197-1 for GBFS (CEN, 2001). Thus, condition (d) is fulfilled.

Taking into account such a change of status from waste to byproducts has proven to drastically modify environmental results of road pavement structures using BFS (Sayagh et al., 2010).

\subsection{Functional unit and system boundaries}

The EN 206-1 standard (CEN, 2004) defines an equivalent binding capacity for additions when they are substituted to type I cement, as defined below:

$\mathrm{BE}=\mathrm{cem}+k \cdot \mathrm{SCM}$

where $B E$ is the binding equivalent value (eq. $\mathrm{kg} / \mathrm{m}^{3}$ ), based on the targeted strength properties of the cement concrete, "cem" is the CEM I cement dosage $\left(\mathrm{kg} / \mathrm{m}^{3}\right), \mathrm{SCM}$ is the dosage of SCM $\left(\mathrm{kg} / \mathrm{m}^{3}\right)$, and $k$ is the coefficient specific of the additive (no unit).

The binding equivalent value has been chosen as the functional unit, in order to compare products with similar concrete strength properties according to the EN 206-1 standard (CEN, 2004). The $k$ parameter equals to 0.6 and 0.9 , for FA and GBFS, respectively, which means that $1 / 0.6 \mathrm{~kg}$ of fly ash will have the same properties as $1 / 0.9 \mathrm{~kg}$ of granulated blast furnace slag and $1 \mathrm{~kg}$ of CEM I. Thus, in this study, $1 \mathrm{~kg}$ of CEM I is compared to $1.11 \mathrm{~kg}$ of GBFS, and to $1.67 \mathrm{~kg}$ of fly ash.

The LCA is restricted to a cradle-to-gate study as it can be justified that the gate-to-grave tree is similar for cement and Supplementary Cementitious Materials, as they are all included in concrete and that the end of life for concretes is, for the moment, the same for all concrete compositions. This restriction has already 


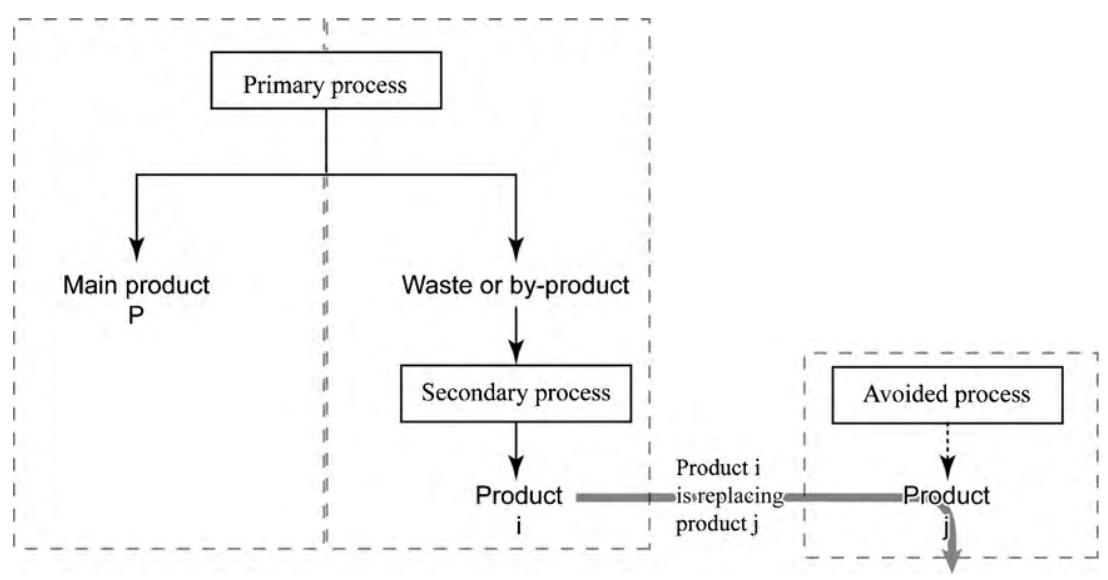

Fig. 1. Description of the different sub-systems involved in the study.

been done in civil engineering LCA studies (e.g. Schuurmans et al., 2005). Concerning the lifespan, it has been supposed that even if the aim of cement or clinker substitution is to reduce environmental burdens for concrete, both equivalent strength and durability performances are achieved as illustrated by the equivalent binding parameter of the EN 206-1 (CEN, 2004) as explained above. Therefore a similar life span has been chosen for all simulations.

\subsection{System decomposition}

In order to define a suitable allocation procedure, two types of processes have been distinguished, within the environmental system as follows. The primary production processes are defined as processes that produce the main product and the by-products or waste, and secondary processes, are defined as processes aiming at treating the by-product or waste to produce a by-product suitable for its further use as a cement concrete component. Fig. 1 presents a schematic view of this distinction. The details of the primary and secondary processes for GBFS and FA are then presented in Fig. 2.

GBFS is co-produced with iron in a blast furnace, this is then considered as primary production process. After the blast furnace processing, GBFS need to be vitrified, in order to develop binding properties suitable with its application as cement substitute (granulation process). The by-product is then grinded to get a similar grain size as clinker. Granulation and grinding belong to the secondary process (Fig. 2a). On the other hand, FA are issued from an electromagnetic process that removes ashes from the exhaust gases of coal power plants (Fig. 2b), and concentrates them (primary production process). FA are then dried and stocked, before being used as a cement additive (secondary process).

\subsection{Sources of environmental and economic data}

For the environmental data, the all-inclusive components are calculated with the original system boundary of the EcoInvent database (Kellenberger and Althaus, 2003). Inputs and outputs data used are from Althaus (2003) for Iron production (primary process) and Dunlap (2003) for slag treatment (secondary process), ATILH (2002) for French CEM I production, Sokka et al. (2005) and Dones et al. (2007) for coal power plants (primary process) and Surschiste (2009) for fly ash treatment (secondary process). According to the production of the different type SCM, production plants have been considered in the inventory using the infrastructure data of the EcoInvent database. These data are presented in the input data table as a percentage of the flow for the infrastructure process (Table 1: infrastructure). The treatment plants have not been taken into account due to the lack of information. However it seems rea- sonable to assume it will be negligible for the final environmental load.

A synthesis of the material flows is presented in Tables 1 and 2 . It has to be noted that the output rate between by-products and products are fixed with the average French production but it is possible to change these output rates by changing the production technology.

For GBFS, prices of iron were obtained from Dahlström and Ekins (2006) and Metal Bulletin (2008) and assumed to be equal to $400 € / t$ of crude iron. Prices for GBFS were fixed at $40 €$ in the literature (Ecocem, 2008; Vinci, pers. com.). Relative prices of electricity and FA were obtained from EDF (2008) and Vinci (pers. com.) and fixed to $0.1 € / \mathrm{kWh}$ and $20 € / \mathrm{t}$ for electricity and $\mathrm{FA}$, respectively. This study focuses on the French context where the availability of fly ash and blast furnace slag is not important. A similar study in another economic context would give different results, however, the methodology presented here can be applied everywhere.

\subsection{Description of allocation procedures}

Different allocation procedures have been considered for the addition of GBFS and FA into cement. All these procedures consider that secondary processes, as they are defined previously in the paper, are entirely allocated to the additive. Differences in allocation procedures thus only concern the primary processes and the LCI.

Therefore the general presentation of the inventory allocation is as follows:

$\vec{F}_{\text {co-product-or-waste }}=C \cdot \vec{F}_{\text {primary process }}+\vec{F}_{\text {secondary process }}$

where $\vec{F}_{\text {co-product-or-waste }}, \vec{F}_{\text {primary process }}$, and $\vec{F}_{\text {secondary process }}$ refer to the flow inventories of environmental burdens of by-product or waste (in our case SCM), primary and secondary processes, respectively, and $C$ is the allocation coefficient that differs whether the allocation mode that is chosen.

As the transformation from the environmental inventory to the environmental impacts corresponds to a matrix $A$, that could be referred as a technology matrix (Heijungs, 1994), impacts for SCM can be expressed by Eq. (3).

$\vec{I}_{\text {co-product-or-waste }}=\bar{A}\left(C \cdot \vec{F}_{\text {primary process }}+\vec{F}_{\text {secondary process }}\right)$

where $\vec{I}$ refers to environmental impacts of the by-product or waste (SCM).

Eq. (3) is equivalent to Eq. (4) where the scalar $C$ is extracted from the matrix product.

$\vec{I}_{\text {co-product-or-waste }}=C \cdot \vec{I}_{\text {primary process }}+\vec{I}_{\text {secondary process }}$ 
(a) System boundary of GBFS manufacturing

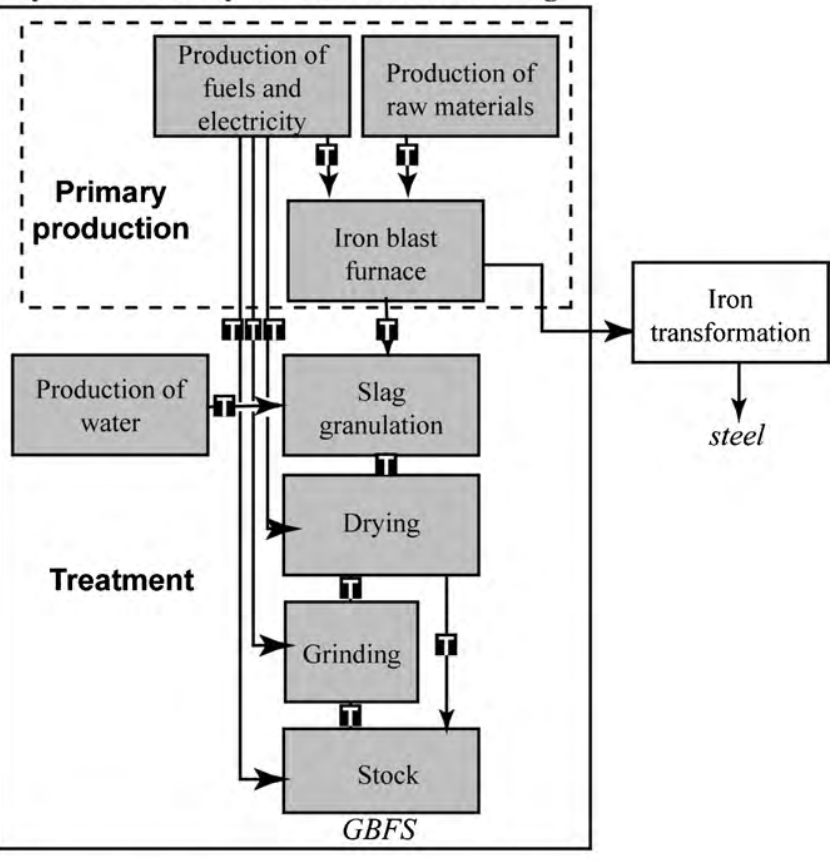

(b) System boundary of fly ash manufacturing

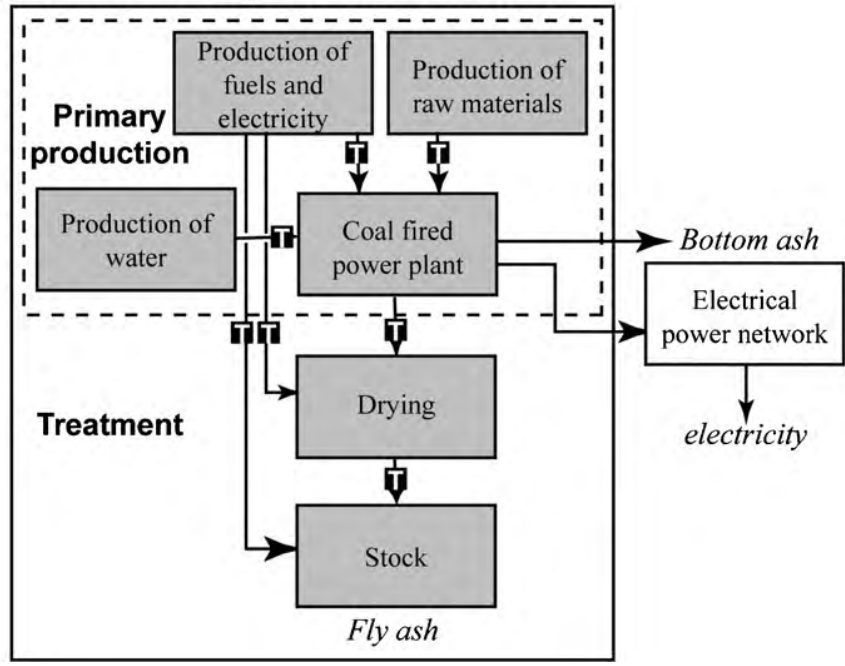

Fig. 2. The studied systems. (a) GBFS production, (b) FA production. Note that distinction is made between a primary production process which produces main products (steel or electricity) and waste (GBFS or fly ash), and a secondary process, that aims to treat waste to produce by-products. White $\mathrm{T}$ in a black square indicates a product transport.

In the case of waste, coefficient $C$ is equal to zero and environmental loads exclusively results from the secondary process as described in Fig. 1.

In the case of by-products, two allocations procedures can be chosen.

The mass allocation coefficient $C_{\mathrm{m}}$ can be calculated as the mass ratio between main product and by-product:

$C_{\mathrm{m}}=\frac{m_{\text {by-product }}}{m_{\text {main product }}+m_{\text {by-product }}}$

where $m_{\text {by-product }}$ and $m_{\text {main product }}$ are the masses of by-product (SCM) and of the main product, respectively.
The economic allocation coefficient $C_{\mathrm{e}}$ is calculated as follows:

$C_{\mathrm{e}}=\frac{(\$ \cdot m)_{\text {by-product }}}{(\$ \cdot m)_{\text {main product }}+(\$ \cdot m)_{\text {by-product }}}$

where $(\$ \cdot m)$ is the price per unit of the materials $(\$)$ multiplied by the mass of materials produced during the process $(m)$.

\subsection{Life Cycle Impact Assessment method}

In literature two main schools of methods for impact assessment are found: (i) pressure-oriented methods such as CML (Guinée et al., 2002) or EDIP (Hauschild and Wenzel, 1998) that restrict quantitative modelling to relatively early stages in the cause-effect chain to limit uncertainties and (ii) damage oriented methods such as Eco-indicator 99 (Goedkoop and Spriensma, 2001) or IMPACT $2002+$ (Jolliet et al., 2003) that try to model the cause-effect chain up to the endpoint, or damage, sometimes with high uncertainties.

In this study the CML pressure-oriented method (Guinée et al., 2002) has been chosen as the purpose is to make distinctions between products, and not between environmental impacts. All the calculations are performed with Simapro (Goedkoop and Oele, 2004) that is a product comparison tool. A previous study concerning sensitivity of GBFS allocation (Sayagh et al., 2010) introduced a classification method, that assigns inventory results to impact categories in order to avoid double counting and magnify the impacts of a particular burden (Reap et al., 2008b). This method was not used in the present study, because it requires site specific data. However, global comparison results should not be affected because using classification coefficients would lead to add a multiplication matrix into Eq. (3).

In addition to CML indicators, energy consumption has also been calculated as it is a strong concern in civil engineering. Energy is calculated with the cumulative energy demand method (CED) that quantifies the energy required during the life cycle of a product (Chapman, 1974; Hirst, 1974). As shown by Huijbregts et al. (2006), fossil cumulative energy demand (CED) is indeed an important driver of several environmental impacts and thereby indicative for many environmental problems. This indicator is therefore redundant with environmental indicators from CML01, particularly the abiotic depletion and global warming for which a strong correlation can be observed for all processes gathered in EcoInvent database (Huijbregts et al., 2006). It should then not be used with CML indicators but rather instead of global warming and abiotic depletion indicators; however, this indicator is used in numerous study in civil engineering. It has then been chosen to analyse it, to provide a comparison possibility (Bouhaya et al., 2009; Asif et al., 2007; Schuurmans et al., 2005). Furthermore CML01 and CED are the primary bases for the construction of the French environmental standards on building construction materials, which are the NF P 01-010 standards (AFNOR, 2004).

\section{Results: environmental impact profiles for mineral addition in concrete}

The allocation coefficients calculated with the different allocation procedures are presented in Table 3 . The data needed to calculate these allocation coefficients with Eqs. (5) and (6) are also presented in the same table. Finally, it has to be reminded that the functional unit is the binding quantity equivalent to $1 \mathrm{~kg}$ of CEM I. Different by-product allocation results are presented, depending on the amount of allocation for the primary production process. No allocation induces that only the by-product treatment is used; allocation by economic or mass value induce that the primary pro- 
Table 1

Inputs for production and treatment of Supplementary Cementitious Materials (SCM).

\begin{tabular}{|c|c|c|c|c|c|}
\hline & \multicolumn{3}{|c|}{ Production of blast furnace slag } & \multicolumn{2}{|l|}{ Production of fly ash } \\
\hline & $\begin{array}{l}1 \mathrm{~kg} \text { pig iron } \\
\text { Furnace }\end{array}$ & $\begin{array}{l}1 \mathrm{~kg} \text { BFSG } \\
\text { Granulation + dewatering }\end{array}$ & $\begin{array}{l}1 \mathrm{~kg} \mathrm{BFSG} \\
\text { Drying + (grinding) + stock }\end{array}$ & $\begin{array}{l}1 \mathrm{kWh} \text { electricity } \\
\text { Coal-fired power plants }\end{array}$ & $\begin{array}{l}1 \mathrm{~kg} \mathrm{FA} \\
\text { Drying + stock }\end{array}$ \\
\hline $\begin{array}{l}\text { Raw materials } \\
\text { Sinter }(\mathrm{kg}) \\
\text { Pellets }(\mathrm{kg}) \\
\text { Lump ore }(\mathrm{kg}) \\
\text { Water }\left(\mathrm{m}^{3}\right)\end{array}$ & $\begin{array}{l}1.05 \\
0.40 \\
0.15\end{array}$ & 0.01 & & 0.035 & \\
\hline $\begin{array}{l}\text { Energy } \\
\text { Hard coal (kg) } \\
\text { Electricity (kWh) } \\
\text { Gaz }(\mathrm{MJ}) \\
\text { Fuel }\left(\mathrm{m}^{3}\right)\end{array}$ & $\begin{array}{l}0.49 \\
0.10\end{array}$ & $2.15 \times 10^{-3}$ & $\begin{array}{l}0.07 \\
3.16 \times 10^{-1} \\
1.14 \times 10^{-6}\end{array}$ & $\begin{array}{l}0.432 \\
1.56 \times 10^{-4}\end{array}$ & $\begin{array}{l}6.82 \times 10^{-3} \\
0.29 \\
1.03 \times 10^{-6}\end{array}$ \\
\hline $\begin{array}{l}\text { Transport } \\
\text { Boat }(\mathrm{t} \mathrm{km}) \\
\text { Train }(\mathrm{t} \mathrm{km}) \\
\text { Truck }(\mathrm{t} \mathrm{km})\end{array}$ & $\begin{array}{l}1.50 \\
0.25 \\
0.01\end{array}$ & $3.0 \times 10^{-3}$ & $5.3 \times 10^{-3}$ & $5.09 \times 10^{-3}$ & $3.0 \times 10^{-3}$ \\
\hline $\begin{array}{l}\text { Installation (unit) } \\
\text { Blast furnace } \\
\text { Coal thermal plant }\end{array}$ & $1.33 \times 10^{-11}$ & & & $1.33 \times 10^{-11}$ & \\
\hline
\end{tabular}

Table 2

Outputs for production and treatment of SCM.

\begin{tabular}{|c|c|c|c|c|c|}
\hline & \multicolumn{3}{|c|}{ Production of blast furnace slag } & \multicolumn{2}{|l|}{ Production of fly ash } \\
\hline & $\begin{array}{l}1 \mathrm{~kg} \text { pig iron } \\
\text { Furnace }\end{array}$ & $\begin{array}{l}1 \mathrm{~kg} \text { BFSG } \\
\text { Granulation + dewatering }\end{array}$ & $\begin{array}{l}1 \mathrm{~kg} \text { BFSG } \\
\text { Drying + (grinding)+ stock }\end{array}$ & $\begin{array}{l}1 \mathrm{kWh} \text { electricity } \\
\text { Coal-fired power plants }\end{array}$ & $\begin{array}{l}1 \mathrm{~kg} \mathrm{FA} \\
\text { Drying + stock }\end{array}$ \\
\hline \multicolumn{6}{|l|}{ Waste } \\
\hline Boues $(\mathrm{kg})$ & $2.5 \times 10^{-2}$ & & 0.0015 & & $8.48 \times 10^{-5}$ \\
\hline Waste water (m) & $1.81 \times 10^{-3}$ & 0.003 & & & \\
\hline Ashes $(\mathrm{kg})$ & $1.28 \times 10^{-2}$ & & & $2.88 \times 10^{-3}$ & \\
\hline \multicolumn{6}{|l|}{ Air emission } \\
\hline Heat (MJ) & 0.49 & & & 5.62 & \\
\hline Ashes (kg) & $3.2 \times 10^{-5}$ & $8.32 \times 10^{-6}$ & $1.29 \times 10^{-4}$ & $3.38 \times 10^{-4}$ & $3.23 \times 10^{-5}$ \\
\hline Chloride hydrogen & & & & $1.26 \times 10^{-4}$ & \\
\hline SOx $(\mathrm{kg})$ & $1.33 \times 10^{-4}$ & $2.07 \times 10^{-4}$ & $6.84 \times 10^{-7}$ & $4.54 \times 10^{-3}$ & $9.13 \times 10^{-8}$ \\
\hline Lead & $6.91 \times 10^{-8}$ & & & $2.32 \times 10^{-7}$ & \\
\hline Nickel & $1.6 \times 10^{-8}$ & & & $1.07 \times 10^{-7}$ & \\
\hline Manganese & $7.45 \times 10^{-8}$ & & & $1.01 \times 10^{-7}$ & \\
\hline Methane & & & $1.2 \times 10^{-6}$ & $1.04 \times 10^{-5}$ & \\
\hline NOx $(\mathrm{kg})$ & $7.98 \times 10^{-5}$ & & $2.17 \times 10^{-5}$ & $1.96 \times 10^{-3}$ & $1.75 \times 10^{-5}$ \\
\hline $\mathrm{H}_{2} \mathrm{~S}(\mathrm{~kg})$ & $1.07 \times 10^{-5}$ & $2.43 \times 10^{-4}$ & & & \\
\hline $\mathrm{CO}(\mathrm{kg})$ & $1.34 \times 10^{-3}$ & $3.54 \times 10^{-5}$ & $1.36 \times 10^{-5}$ & $8.16 \times 10^{-5}$ & $9.05 \times 10^{-6}$ \\
\hline Dioxins (kg) & $2.66 \times 10^{-15}$ & & & $7.14 \times 10^{-14}$ & \\
\hline $\mathrm{CO}_{2}(\mathrm{~kg})$ & $8.49 \times 10^{-1}$ & & & 0.95 & \\
\hline \multicolumn{6}{|l|}{ Products } \\
\hline Pig iron (kg) & 1 & & & & \\
\hline Slag for crystallisation (kg) & 0.1 & & & & \\
\hline Slag for granulation $(\mathrm{kg})$ & 0.24 & & & & \\
\hline BFSG & & 1 & 1 & & \\
\hline Electricity (kWh) & & & & 1 & \\
\hline Fly ash (kg) & & & & 0.052 & 1 \\
\hline Bottom ash (kg) & & & & 0.014 & \\
\hline
\end{tabular}

Table 3

Allocation percentage used for fly ash (FA) and granulated blast furnace slag (GBFS) for two different allocation procedures. Individual mass and prices are presented to justify the results.

\begin{tabular}{llllr}
\hline Product & Mass produced & Market price & Allocation by mass value & Allocation by economic value \\
\hline Steel & $1 \mathrm{~kg}$ & $400 € / \mathrm{t}$ & $80.6 \%$ & $97.7 \%$ \\
BFSG & $0.24 \mathrm{~kg}$ & $40 € / \mathrm{t}$ & $19.4 \%$ & $2.3 \%$ \\
Electricity & $1 \mathrm{kwh}$ a & $0.1 € / \mathrm{kWh}$ & $87.6 \%$ & $99.0 \%$ \\
FA & $0.052 \mathrm{~kg}$ & $20 € / \mathrm{t}$ & $12.4 \%$ & $1.0 \%$ \\
\hline
\end{tabular}

a Equivalent to $0.367 \mathrm{~kg}$ of hard coal used to produce electricity. The remaining produced fly ash and bottom ash. 
duction impacts are considered relatively to the economic or the mass value of by-products.

\subsection{Environmental impacts for GBFS}

The results of the tested allocation procedures for the use of GBFS as SCM, are presented in Fig. 3 and Table 4. Please note that for Fig. 3, the scale is logarithmic and results are presented in percentages relatively to the CEM I cement values.

These results show that considering GBFS as waste (no allocation) conducts to a lower environmental impacts than CEM I (Fig. 3, no allocation procedure and Table 4 ). The highest contributions are related to fresh and marine ecotoxicity and represent $50 \%$ of those of $1 \mathrm{~kg}$ of CEM I.

When an allocation by mass ratio is chosen, all environmental impacts are much higher than those of CEM I.

When economic allocation procedure is chosen, Fig. 3 shows that the partial load from the primary production process has an important effect on environmental indicators such as abiotic depletion, human toxicity, photochemical oxidation, fresh and marine water ecotoxicity that are higher than those from CEM I. However, global warming impacts are still relatively low compared to CEM I.

This feature could be explained by the fact that due to the high conductivity of metals, heating in the blast furnace is done with electricity which has a low $\mathrm{CO}_{2}$ impact compared to the fuels that have to be burnt in the cement kilns. On the contrary the raw material extraction for iron industry has much more impacts than the limestone extraction for cement in terms of water pollution.

\subsection{Environmental impacts for $F A$}

The results of the three tested allocation procedures for the use of FA as a SCM are presented in Table 4 and Fig. 4. For Fig. 4, the scale is logarithmic the results are presented in percentages relatively to the CEM I cement values.

Impacts of FA when only accounting for secondary processes (no allocation), are, as for GBFS, negligible compared to the environmental impacts of cement production. They represent less than $25 \%$ of the impacts of CEM I production for all environmental indicators (Table 4).

When an allocation by mass ratio is chosen, as for GBFS, all environmental impacts are much higher than those of CEM I.

When economic allocation procedure is chosen, Fig. 4 shows that a partial load from the primary production process induces a strong impact for FA. Environmental impacts are similar or higher than cement for the majority of indicator categories. These high environmental loads can be firstly explained by the nature of the production system. Actually, FA are by-products from coal power plants that are emitting large quantities of airborne pollutants $\left(\mathrm{CO}_{2}\right.$, $\mathrm{NO}_{2}, \mathrm{SO}_{2}$ ). Therefore even a small impact allocation by relative economic value strongly affects the environmental indicators. It can also be explained by the weak binding properties of FA compared to CEM I, which induces a low $k$ value in Eq. (1) and therefore leads to compare $1.67 \mathrm{~kg}$ of FA with $1 \mathrm{~kg}$ of CEM I.

\section{Discussion}

The results of waste use as regards allocation procedure for environmental impacts have been investigated within LCA framework, some relevant limitations and issues are discussed below.

\subsection{Limitations due to waste performances with time compared to CEM I}

It has to be noted that for the moment cement or clinker substitutions that represent more than $50 \%$ of the whole cementitious

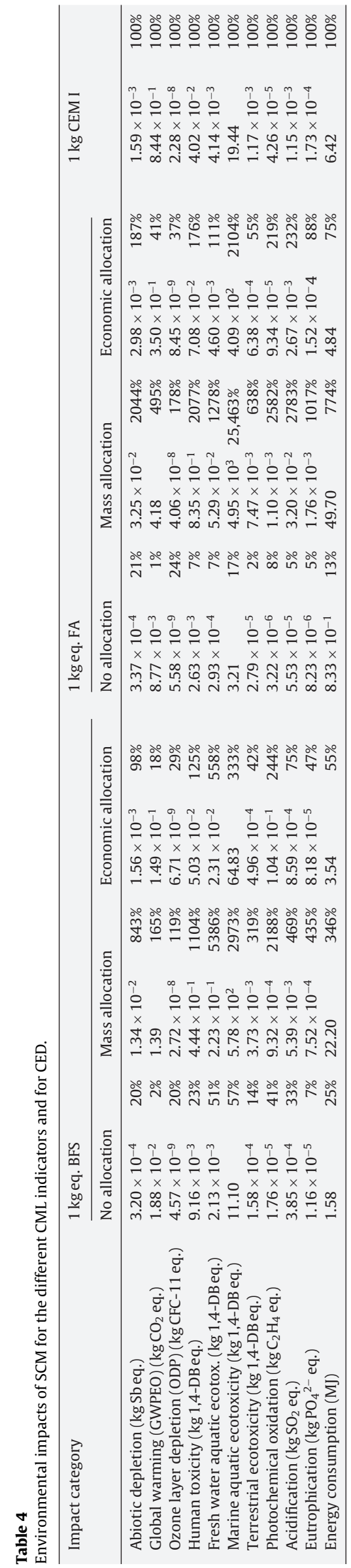




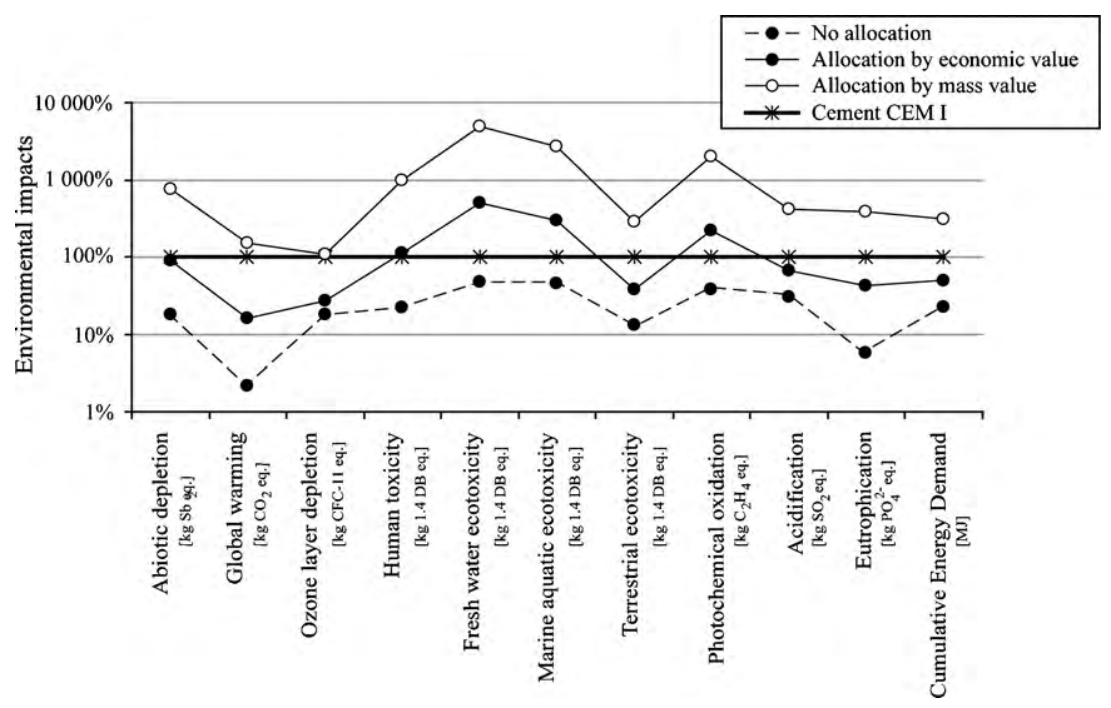

Fig. 3. Environmental impact of a mass of GBFS (1.11 kg) equivalent to the replacement of $1 \mathrm{~kg}$ of cement CEM I, for the different CML indicators and for CED, with different allocation procedures.

phase are subjected to decrease durability properties by increasing carbonation rate (e.g. Osborne, 1999; Sisomphon and Franke, 2007; Habert and Roussel, 2009). These effects are not considered in this study. They would however have a pregnant importance for studies that compare structural solutions in civil engineering applications.

\subsection{Comparison between allocation procedures}

SETAC strongly recommends to rely the allocation procedure primarily upon physicochemical considerations (Lundie et al., 2007). The ISO standard for LCA (ISO, 2006) proposes a preference order of different options to be checked on their applicability one after the other. This preference order consists firstly to try to avoid the allocation by dividing the process into sub-processes, then if allocation cannot be avoided, to apply principles of physical causality for allocation of the burdens, such as mass or energetic value; and finally to apply other principles of causality such as economic value.

All methods developed in this article respect the SETAC recommendations by introducing the concept of primary and secondary processes, this last being physicochemically specific for the pro- duction of the by-product or waste. Thus, concerning waste, only secondary processes should be accounted for. However, allocations methods tested in this paper concern the part of the primary process which can be attributed to waste becoming by-products according to the new EU regulation (EU, 2008).

Few studies have dealt with by-product allocation in the building construction industry. Schuurmans et al. (2005) have studied the environmental evaluation of fine sand that is considered as a byproduct in gravel quarries. An economic allocation has been chosen without evaluation of the effects of other allocation modes. Sayagh et al. (2010) is the only civil engineering oriented publication that studied the effect of BFS mass allocation procedure for the environmental evaluation of environmental impact of road works. But the majority of the studies that seem close to the specific objectives of the present study have been found in primary sector (fisheries and pigs production) (Ayer et al., 2007; Basset-Mens and van der Werf, 2005), as they deal with the introduction of a by-product from a different industrial sector into a process. For instance the use of soy cakes as feed ingredients in the pig production whereas this soy cake results from the soy industry that is dealing with oil production (Basset-Mens and van der Werf, 2005).

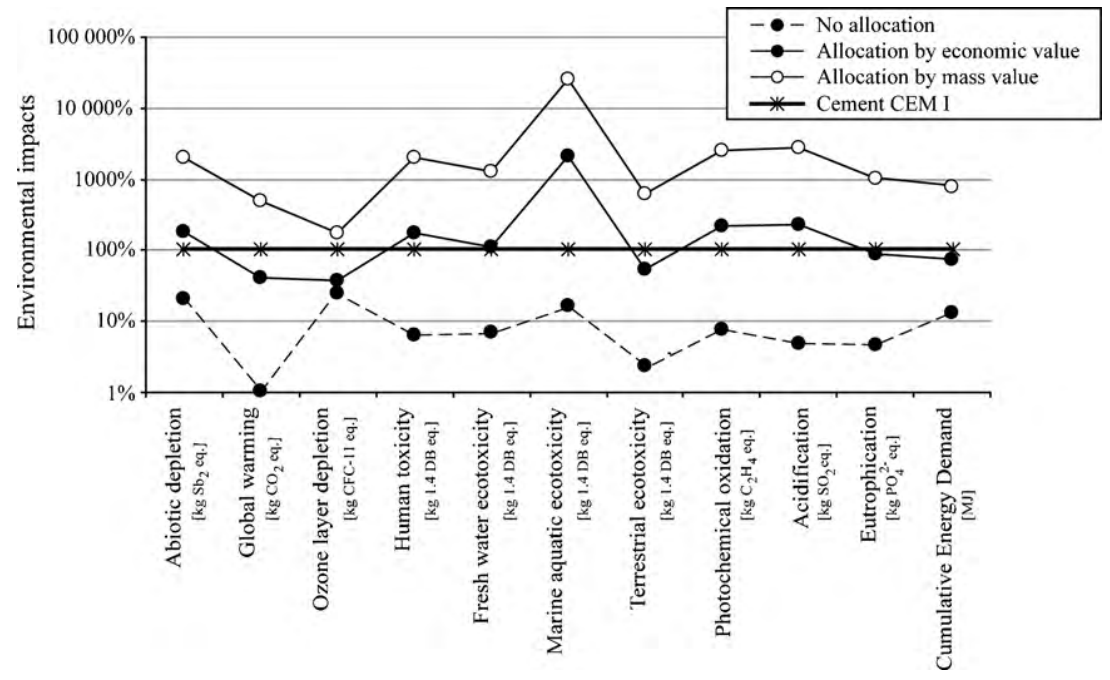

Fig. 4. Environmental impact of a mass of fly ash $(1.67 \mathrm{~kg})$ equivalent to the replacement of $1 \mathrm{~kg}$ of cement CEM I, for the different CML indicators and for CED, with different allocation procedures. 
The mass allocation procedure presents the advantage to be relatively constant with time, the mass ratio between product and by-product being rarely variable, unless a technological improvement occurs. However, in many cases, mass of by-product can be tremendously above the one of the main product, especially for high economic value added product. For instance, in the case of oil refined products, mass residues of distillation processes are the most important ones. For this last case, some authors suggest to perform allocation according to the energetic value of products (Wang et al., 2004): the economic value added of oil refined products is precisely largely linked to their energy content. In the case of SCM, instead of energy content, the economic added value is linked to their binding properties.

In a world-wide context governed by trade offer and goods fluxes, the economic allocation procedure can be more suitable than mass allocation, as it takes into account the economic value added of main products and by-products. In many studies, economic allocation is often preferred as it highlights the driving forces of the industry (Ziegler and Hansson, 2003; Ayer et al., 2007). However, this method has the disadvantage to be unstable because of potential market prices fluctuations.

\subsection{Allocation procedures versus system expansion}

Some studies use the substitution method to calculate the environmental burdens of waste by considering the avoided burdens. This substitution method is not clearly mentioned in the ISO standards, however several authors (Tillman et al., 1994; Heijungs and Guinée, 2007) have shown that system expansion, which is mentioned in ISO 14040 and the substitution method are conceptually equivalent.

A first example of this method is the one of IISI (2002) that performs the inventory of steel. In that case, produced BFS are considered to replace natural aggregates inside road structures. Thus, the contribution of natural aggregates production is considered avoided and subtracted to the environmental load of the main product. This system expansion method appears dedicated to the evaluation of main products.

Using the system expansion method as well, Babbitt and Lindner (2008) have applied it to by-products, calculating the life cycle inventory for coal combustion FA. They subtract environmental burdens of the clinker production that have been avoided by FA use instead of CEM I. Babbitt and Lindner (2008) consider FA as a waste and therefore affect a null value for $C$ in Eq. (3) but still consider the impacts of the secondary processes. But a mass allocation method has been used as well in similar studies (Benetto et al., 2004; Lee and Park, 2005).

Based on system boundaries (Fig. 1) without system expansion or allocation methods, the environmental load of both main product (product P, Fig. 1) and by-product (product i, Fig. 1) is logically found as the total contribution of primary and secondary processes as expressed in the following equation:

$\overrightarrow{F_{P}}+\vec{F}_{\mathrm{i}}=m_{\mathrm{P}} \cdot \vec{F}_{\text {primary process }}+m_{\mathrm{i}} \cdot \vec{F}_{\text {secondary process }}$

Considering mass and energy conservation laws, this relationship should be encountered using system expansion method.

Using the expansion method of IISI (2002), and according to the defined system boundaries in Fig. 1, the environmental load of the main product $\mathrm{P}$ is expressed as:

$\overrightarrow{F_{P}}=m_{\mathrm{P}} \cdot \vec{F}_{\text {primary process }}-m_{\mathrm{j}} \cdot \vec{F}_{\text {avoided process }}$

Then using the expansion method of Benetto et al. (2004), Lee and Park (2005) and Babbitt and Lindner (2008), and according to the defined system boundaries in Fig. 1, the environmental load of the by-product $i$ is expressed as:

$\vec{F}_{i}=C \cdot \vec{F}_{\text {primary process }}+m_{\mathrm{i}} \cdot \vec{F}_{\text {secondary process }}-m_{\mathrm{j}} \cdot \vec{F}_{\text {avoided process }}(9)$

Considering no allocation, i.e. $C=0$, then the addition of Eqs. (8) and (9) gives:

$$
\begin{aligned}
\vec{F}_{\mathrm{P}}+\vec{F}_{\mathrm{i}}= & m_{\mathrm{P}} \cdot \vec{F}_{\text {primary process }}+m_{\mathrm{i}} \cdot \vec{F}_{\text {secondary process }}-2 m_{\mathrm{j}} \\
& \vec{F}_{\text {avoided process }}
\end{aligned}
$$

Eq. (10) is not equivalent to Eq. (8). This mainly shows that the system expansion method, although it can appear coherent for the study of one product or one by-product alone, does not respect mass conservation when both products are considered together. This method is in fact highly dependant of the point of view of the LCA performer, as the choice of the system boundaries is always done in accordance with the objective of the study. The consequence of this method is that environmental loads can be subtracted from any product as soon as a multi-product process does exist. Furthermore, it is not adapted to waste or by-product users, because the environmental benefits that they can generate by reusing or recycling, are ultimately attributed to the waste producers. At the difference with mass, energetic or economic allocation procedures, there is no global coherency between various studies defining different system boundaries.

\subsection{Waste/product mass weighted price for impact allocation}

As written above, the economic allocation method has the disadvantage to be unstable because of potential market prices fluctuations. However at the difference with other industrial systems, by-products in cement and concrete sector are not only used for economic reasons, but also for environmental reasons. Therefore, it seems justified to consider differently the allocation procedure as it is usually done in literature. The matter is then to answer the following question: what would be the acceptable by-product/product selling price ratio ensuring an acceptable environmental impact? The environmental impact, noted as $\alpha_{\mathrm{e}}$, can be written as the ratio of the impact of the mass of by-product that has equivalent binding properties as one $\mathrm{kg}$ of CEM I compared to the impact of $1 \mathrm{~kg}$ of CEM I. $\alpha_{\mathrm{e}}$ can then be expressed as Eq. (11) if the binding equivalent explained in Eq. (1) is used.

$\alpha_{\mathrm{e}}=\frac{I_{\text {by-product }}}{k \cdot I_{\text {cement }}}$

where $I_{\text {by-product }}$ is the impact of the production of $1 \mathrm{~kg}$ of byproduct, $k$ is the activity coefficient of the by-product and $I_{\text {cement }}$ is the environmental impact of $1 \mathrm{~kg}$ of cement. Using Eq. (4) $\alpha_{\mathrm{e}}$ can be written as follows.

$\alpha_{\mathrm{e}}=\frac{C \cdot I_{\text {primary process }}+I_{\text {secondary process }}}{k \cdot I_{\text {cement }}}$

Finally Eq. (6) induces that the environmental impact ratio can be expressed as formula (13).

$$
\alpha_{\mathrm{e}}=\frac{\left((\$ \cdot m)_{\text {by-product }} /\left((\$ \cdot m)_{\text {main product }}+(\$ \cdot m)_{\text {by-product }}\right)\right)}{I_{\text {primary process }}+I_{\text {secondary process }}}
$$

From Eq. (13) it is possible to extract the by-product/product price ratio that is important to look at in order to answer to the previous question of: what would be the acceptable by-product/product selling price ratio ensuring an acceptable environmental impact? The price ratio is definedin 
Eq. (14).

$$
\begin{aligned}
\frac{\$_{\text {main product }}}{\$_{\text {by-product }}}= & \frac{m_{\text {by-product }}}{m_{\text {main product }}}\left[\frac{I_{\text {primary process }}}{I_{\text {cement }}}\right. \\
& \left.\cdot \frac{1}{k \alpha_{e}-\left(I_{\text {secondary process }} / I_{\text {cement }}\right)}-1\right]
\end{aligned}
$$

where $\$$ are the price per kilogram of the different products produced in the blast furnace or in the coal power plant, $m_{\text {by-product }} / m_{\text {main product }}$ is the mass ratio produced by the primary process, $I_{\text {primary process }}$ is the impact of the primary process, $k$ is the activity coefficient used to calculate the equivalent binding in Eq. (1) and $\alpha_{\mathrm{e}}$ is the environmental ratio that is found tolerable in order to provide an environmental advantage for the cement industry when slags or fly ash are used as clinker substitution.

In Eq. (11), the economic ratio depends on the technical parameter $k$, representing the acceptable substitution ratio for GBFS or FA in replacement of CEM I. Actually, $k$ can be varied by improving the secondary process, i.e. for FA, $k$ usually varies from 0.4 to 0.6 , and some GBFS can gave a binding equivalent equal to 1 if they are very finely ground.

Secondly, the economic ratio also depends on $\alpha_{\mathrm{e}}$ that is the tolerance assigned to environmental performances, i.e. "using BFS in replacement of CEM I should not contribute to exceed more than $10 \%$ of the greenhouse gas emitted by CEM I". Thus $\alpha_{\mathrm{e}}$ represents a political choice. It can be set at different values for each impact indicator.

Thirdly, the economic ratio depends both on the upstream production (primary and secondary processes) and on the downstream production (i.e. usage of the waste or by-product). On the contrary of system expansion methods, the allocation is the same for a waste or by-product producer or as well as for a waste or by-product user.

Finally, considering that environmental burdens are always distributed following the economic allocation (Eq. (6)), Eq. (14) can be used in two senses:

- Once the environmental efficiency, set by a political decision, is known the optimal economic ratio can be calculated and compared to effective selling prices of main product and by-product. Hence it could help to define economic regulation policies in order to favour more efficient recycling industrial branches.

- Or, if the selling prices ratio is known, $\alpha_{\mathrm{e}}$ can be calculated. It shows the environmental efficiency of a by-product depending on the Upstream/downstream impact ratio. From the waste user point of view, this helps to set a reasonable price in order to ensure the environmental benefit that are chosen by politics. From the waste producer point of view it helps to choose the appropriate recycling application that assure the biggest environmental difference between its by-product and the substituted product in order to get the highest price for its by-product.

In fact, Eq. (14) could be generalised to any waste or by-product:

$$
\begin{aligned}
\frac{\$_{\text {by-product }}}{\$_{\text {main product }}}= & {\left[\frac { m _ { \text { by-product } } } { m _ { \text { main product } } } \left(\frac{I_{\text {primary process }}}{I_{\text {recycling process }}}\right.\right.} \\
& \left.\left.\cdot \frac{1}{\tau \cdot \alpha_{\mathrm{e}}-\left(I_{\text {secondary process }} / I_{\text {recycling process }}\right)}-1\right)\right]^{-1}
\end{aligned}
$$

$\tau$ being a substitution rate of the by-product in replacement of the initial product keeping similar technical performances. The cost ratio of Eq. (15) is the opposite of the one in Eq. (14) in order to allow for a null price for the by-product. The interest of Eq. (15) should be more deeply examined into the global context of economic models, but this goes beyond the purpose of the present paper.

\section{Conclusion}

The revision of the status of waste by the new EU regulation, accounting that those can be economically profitable, results in considering that they also can generate pollution themselves. The question then to take them into account in environmental evaluations, especially through the choice of LCA allocation procedure is essential. Mass and economic allocations have been tested on SCM, that are concerned by the new EU regulation, and prove to have large consequences on environmental loads of SCM.

The mass allocation procedure presents the advantage to be constant over long periods of time. In the present case however, it induces large impacts on by-products that are used in cement industry. It is an advantage for blast furnace and coal industries as waste are taken into account by other sectors. But, as substitutions of clinker are used in cement to lower environmental impacts, this type of allocation by mass without considering any other advantage as regards to resources saving can induce cement industry to stop their use and prefer usual clinker. Besides, the economic allocation presents the advantage of lowering impacts of by-products when compared to the mass allocation. It enhances the fact that the alternative resources are primarily waste and should therefore not have the same environmental burden as the main products. However, this method has the disadvantage to be unstable because of potential market prices fluctuations. Thus no allocation method appears incontestable; they are all the results of the LCA practitioner's choice.

Hence, authors suggest that the choice of the environmental load should be set by political decision and that once this decision is made, other technical and economic relations can affect the allocation and allow for an economic and environmental optimum for recycling. Finally, this study has shown that all these allocation methods, even if perfectible, are still preferable to the system expansion method, because system expansion does not ensure a global coherency between various LCA studies.

\section{Acknowledgments}

C. Chen and G. Habert wish to thank the French competitiveness cluster Advancity and the Region Ile de France for their financial help.

\section{References}

AFNOR, French Standardisation Agency. Environmental quality of construction products-environmental and health declaration of construction products. AFNOR; 2004, 47 pp.

Althaus H-J. Life Cycle Inventories of Metals. Final report ecoinvent 2000. No. 10. Dübendorf: Swiss Centre for Life Cycle Inventories; 2003, 682 pp.

Asif M, Muneer T, Kelley R. Life cycle assessment: a case study of a dwelling home in Scotland. Build Environ 2007;42:391-1394.

ATILH. Environmental evaluation of French cement production. Ecobilan S.A; 2002, 12 pp. [in French].

Ayer NW, Tyedmers PH, Pelletier NL, Sonesson U, Scholz A. Co-product allocation in life cycle assessments of seafood production systems: review of problems and strategies. Int J Life Cycle Assess 2007;12:480-7.

Babbitt CW, Lindner AS. A life cycle comparison of disposal and beneficial use of coal combustion products in Florida. Part 1: methodology and inventory of materials, energy and emissions. Int J LCA 2008;13:202-11.

Basset-Mens C, van der Werf HMG. Scenario-based environmental assessment of farming systems: the case of pig production in France. Agric Ecosyst Environ 2005;105:127-44.

Benetto E, Rousseaux P, Blondin J. Life cycle assessment of coal by-products based electric power production scenarios. Fuel 2004;83:957-70.

Bouhaya L, Le Roy R, Feraille-Fresnet A. Simplified environmental study on innovative bridge structure. Environ Sci Technol 2009;43:2066-71.

CEN, European Committee for Standardization. NF EN 197-1. Cement-part 1: composition, specifications and conformity criteria for common cements; 2001.

CEN, European Committee for Standardization. NF EN 206-1. Concrete-part I: specification, performance, production and conformity; 2004.

CEN, European Committee for Standardization. NF EN 450-1. Fly ash for concrete-part 1: definition, specifications and conformity criteria; 2007. 
Chapman PF. Energy costs: a review of methods. Energy Policy 1974;2:91-103.

Dahlström K, Ekins P. Combining economic and environmental dimensions: value chain analysis of UK iron and steel flows. Ecol Econ 2006;58:507-19.

Dones R, Bauer C, Bollinger R, Burger B, Faist Emmenegger M, Frischknecht R, et al Life Cycle Inventories of Energy Systems: results for current systems in Switzerland and other UCTE countries. Ecoinvent report no. 5. Dübendorf, $\mathrm{CH}$ : Paul Scherrer Institut Villigen, Swiss Centre for Life Cycle Inventories; 2007.

Dunlap R. Life cycle inventory of slag cement manufacturing process: project CTL No. 312012. Illinois: Construction Technology Laboratories; 2003, 13 pp.

Ecocem. Producer of ground granulated blastfurnace slag (GGBS); 2008.

Ekvall T, Finnveden G. Allocation in ISO 14041-a critical review. J Clean Prod 2001;9:197-208.

European Union. Directive 2008/98/EC of the European parliament and of the counci on waste and repealing certain directives. Off J Eur Union 2008;L312:3-30.

Finnveden G. Methodological aspects of life cycle assessment of integrated solid waste management systems. Resour Conserv Recycl 1999;26:173-87.

Flower DJM, Sanjayan JG. Greenhouse gas emissions due to concrete manufacture Int J Life Cycle Assess 2007;12:282-8.

Frichknecht R. Allocation in Life Cycle Inventory Analysis for joint production. Int LCA 2000;5:85-95.

Gartner E. Industrially interesting approaches to "low- $\mathrm{CO}_{2}$ " cements. Cem Concr Res 2004;34:1489-98.

Goedkoop M, Oele M. Simapro database manual, methods library. PRe Consultants BV; 2004.

Goedkoop M, Spriensma R. The Eco-indicator 99, a damage oriented method for Life Cycle Impact Assessment, methodology report. PRe Consultants BV; 2001, 132 pp.

Habert G, Roussel N. Study of two concrete mix-design strategies to reach carbon mitigation objectives. Cem Concr Comp 2009;31:397-402.

Hauschild M, Wenzel H. Environmental assessment of products-vol. 2: scientific background. London: Chapman \& Hall; 1998.

Heijungs R, Guinée JB. Allocation and 'what if' scenarios in life cycle assessment of waste management systems. Waste Manage 2007;27:997-1005.

Heijungs R. A generic method for the identification of options for cleaner products. Ecol Econ 1994;10:69-81.

Hendricks CA, Worrell E, Price L, Martin N. Emission reduction of greenhouse gases from the cement industry. In: 4th international conference on greenhouse gas control technologies; 1998.

Hirst E. Food-related energy requirements. Science 1974;184:177-83.

Huijbregts MAJ, Linda JA, Rombouts LJA, Hellweg S, Frischknecht R, Hendriks AJ, et al. Is cumulative fossil energy demand a useful indicator for the environmental performance of products? Environ Sci Technol 2006;40:641-8.

IISI, International Iron Steel Institute. World Steel Life Cycle Inventory. Methodology report. Brussels: Committee on Environmental Affairs; 2002.

ISO, International Standardisation Organisation. ISO 14040: environmenta management-life cycle assessment-principles and framework; ISO 14040 International Standardisation Organisation; 2006.
Jolliet O, Margni M, Charles R, Humbert S, Payet J, Rebitzer G, et al. IMPACT 2002+ a new Life Cycle Impact Assessment methodology. Int J LCA 2003;8:324-30.

Kawai K, Sugiyama T, Kobayashi K, Sano S. Inventory data and case studies for environmental performance evaluation of concrete structure construction. J Adv Concr Technol 2005:3:435-56.

Kellenberger D, Althaus H-J. Life Cycle Inventories of building products, final report EcoInvent. EMPA Dübendorf: Swiss Centre for Life Cycle Inventories; 2003.

Kelly TD, Van Oss HG. Compiled data for cement statistics. U.S. Geological Survey; 2008.

Lee K-M, Park P-J. Estimation of the environmental credit for the recycling of granulated blast furnace slag based on LCA. Res Cons Recycl 2005;44:139-51.

Lundie S, Ciroth A, Huppes G. Inventory methods in LCA: towards consistency and improvement. Final report. UNEP-SETAC Life Cycle Initiative; 2007.

Metal Bulletin. Ferrous and non-ferrous market prices 2004-2008; 2008, http://www.metalbulletin.com.

Osborne GJ. Durability of Portland blast-furnace slag cement concrete. Cem Concr Comp 1999;21:11-21.

Reap J, Roman F, Duncan S, Bras B. A survey of unresolved problems in life cycle assessment. Part I: goals and scope and inventory analysis. Int J Life Cycle Assess 2008a;13:290-300.

Reap J, Roman F, Duncan S, Bras B. A survey of unresolved problems in life cycle assessment. Part II: impact assessment and interpretation. Int J Life Cycle Assess 2008b; 13:374-88.

Sayagh S, Ventura A, Hoang T, François D, Jullien A. Sensitivity of the LCA allocation procedure for BFS recycled into pavement structures. Resour Conserv Recycl 2010;54:348-58.

Schuurmans A, Rouwette R, Vonk N, Broers JW, Rijnsburger HA, Pietersen HS. LCA of finer sand in concrete. Int J Life Cycle Assess 2005;10:131-5.

Sisomphon K, Franke L. Carbonation rates of concretes containing high volume of pozzolanic materials. Cem Concr Res 2007;37:1647-53.

Sokka L, Koskela S, Seppälä J. Life Cycle Inventory Analysis of hard coal based electricity generation. The Finnish environment 797. Helsinki: Finnish Environmen Institute; 2005.

Surschiste. Production of fly ash from coal power plants. Available on line: http://www.surschiste.com/page_menu.php?id=9; 2009 [05.12.09].

Tillman A-M, Ekvall T, Baumann H, Rydberg T. Choice of system boundaries in life cycle assessment. J Clean Prod 1994;2:21-9.

Wang $\mathrm{M}$, Lee $\mathrm{H}$, Molburg J. Allocation of energy use in petroleum refineries to petroleum products. Implications for Life-Cycle Use and Emission Inventory of Petroleum Transportation Fuels. Int J LCA 2004;9(1):34-44.

Weidema BP. Avoiding co-product allocation in life cycle assessment. J Ind Ecol 2001;4:11-33.

Xing S, Xu Z, Jun G. Inventory analysis of LCA on steel- and concrete-construction office buildings. Energy Buildings 2008;40:1188-93.

Ziegler F, Hansson PA. Emisssions from fuel combustion in Swedish cod fishery. J Clean Prod 2003;11:303-14. 